Check for updates

Cite this: RSC Adv., 2019, 9, 7723

\title{
Improving gas sensing performance by oxygen vacancies in sub-stoichiometric $\mathrm{WO}_{3-x}$
}

\author{
Weiwei Yu, ab Zhenguang Shen, ${ }^{c}$ Fang Peng, ${ }^{a b}$ Yue Lu, ${ }^{a}$ Meiying Ge, ${ }^{d}$ Xiuli Fu, (DD ${ }^{c}$ \\ Yan Sun, (D) Xin Chen ${ }^{\star a}$ and Ning Dai ${ }^{\star a}$
}

Sub-stoichiometric $\mathrm{WO}_{3-x}$ has provided an alternative platform to investigate oxygen vacancies in gas sensors based on metal-oxides. We present an experimental study on the influence of substoichiometric $\mathrm{WO}_{3-x}$ phase upon gas sensing performance. High-quality $\mathrm{WO}_{3-x}$ nanostructures with several $x$ values $\left(\mathrm{WO}_{3}, \mathrm{~W}_{19} \mathrm{O}_{55}, \mathrm{~W}_{5} \mathrm{O}_{14}, \mathrm{~W}_{18} \mathrm{O}_{49}\right)$ were synthesized and used to fabricate $\mathrm{H}_{2} \mathrm{~S}$ gas sensors. Temperature programmed desorption of oxygen $\left(\mathrm{O}_{2}\right.$-TPD) shows that oxygen absorption behaviors of the as-prepared $\mathrm{WO}_{3-x}$ nanostructures are affected by oxygen vacancies, which played a critical role in the detection of $\mathrm{H}_{2} \mathrm{~S}$ at varying temperature range. We find that oxygen vacancies in sub-stoichiometric $\mathrm{WO}_{3-x}$ facilitate the ionosorption process and in turn enhance the performance of the gas sensor.

Received 6th January 2019

Accepted 23rd February 2019

DOI: 10.1039/c9ra00116f

rsc.li/rsc-advances form. ${ }^{19-21}$ In fact, sub-stoichiometric $\mathrm{WO}_{3-x}$ materials have provided a powerful platform to investigate the gas sensing behaviour associated with oxygen vacancies in metal-oxides based gas sensors. However, it is a challenging task to control oxygen vacancies in sub-stoichiometric $\mathrm{WO}_{3-x}$ accurately.

In this work, we synthesised several sub-stoichiometric $\mathrm{WO}_{3-x}$, including $\mathrm{W}_{19} \mathrm{O}_{55}, \mathrm{~W}_{5} \mathrm{O}_{14}$ and $\mathrm{W}_{18} \mathrm{O}_{49}$, and fabricated gas sensors using the materials. We systematically studied the role of oxygen vacancies in sensing properties of the gas sensors. It was found that oxygen vacancies affected oxygen absorption on the surface of the $\mathrm{WO}_{3-x}$ nanostructures, and facilitated the ionosorption process, favourable for improving device performance and lowering operating temperature. Manipulation of oxygen vacancies in metal oxides brings us an alternative way to improve the performance of gas sensing devices.

\section{Experimental}

\section{Synthesis of tungsten oxide samples}

$\mathrm{WO}_{3}$ powder was synthesized in a typical hydrothermal method as we had reported before. ${ }^{22}$ The sub-stoichiometric tungsten oxides (e.g. $\mathrm{W}_{19} \mathrm{O}_{55}, \mathrm{~W}_{5} \mathrm{O}_{14}, \mathrm{~W}_{18} \mathrm{O}_{49}$ ) were obtained by the reduction of $\mathrm{WO}_{3}$ powders with $\mathrm{S}$ powders. The chemical compositions in the sub-stoichiometric tungsten oxides were controlled by the growth temperature. In the growth system, the as-prepared $\mathrm{WO}_{3}$ powder was located in the middle of a vacuum tube furnace, while $\mathrm{S}$ powder was deposited at its upstream position. After evacuating pre-treatment and repeating flush with pure Ar gas, the tube furnace was heated up to the target temperature and dwelled for one hour. ${ }^{23}$ The raw $\mathrm{WO}_{3}$ powders were then annealed at $500{ }^{\circ} \mathrm{C}$ in atmospheric environment. $\mathrm{W}_{19} \mathrm{O}_{55}$ (dark-blue), $\mathrm{W}_{5} \mathrm{O}_{14}$ (purple-blue), and $\mathrm{W}_{18} \mathrm{O}_{49}$ (purple-
${ }^{a}$ State Key Laboratory of Infrared Physics, Shanghai Institute of Technical Physics, Chinese Academy of Sciences, Shanghai 200083, China. E-mail: xinchen@mail.sitp. ac.cn; ndai@mail.sitp.ac.cn

${ }^{b}$ University of Chinese Academy of Sciences, Beijing 100049, China

${ }^{c}$ School of Science, Beijing University of Posts and Telecommunications, Beijing 100876, China

${ }^{d}$ National Engineering Research Center for Nanotechnology, No. 28 East Jiang Chuan Road, Shanghai 200241, China 
red) were synthesized at $950,1050,1150{ }^{\circ} \mathrm{C}$ in the vacuum tube furnace, respectively. The corresponding colours of the resulting sub-stoichiometric tungsten oxides depend on their chemical compositions, as reported in literatures. ${ }^{19,24-26}$

\section{Sample characterization and gas sensors measurements}

The morphologies of the obtained sub-stoichiometric nanomaterials were examined by a field emission scanning electron microscope (SEM, FEI Sirion 200). Transmission electron microscopy (TEM) and high-resolution transmission electron microscopy (HRTEM, JEOL2100F transmission electron microscope) was adopted to study the crystallographic structures. The phase and composition were investigated by X-ray diffractometry (XRD, Bruker D8 Avance) with a $\mathrm{Cu} \mathrm{K} \alpha$ radiation source (40 $\mathrm{kV}$ and $40 \mathrm{~mA}$ ). X-ray photoelectron spectrometer (XPS, ESCALAB 250Xi, Thermo Scientific) was employed to identify the elements and chemical states by using sub-monochromatized Al KR X-ray as the excitation source. The spectrometer was calibrated with the binding energy of the C 1s line $(284.5 \mathrm{eV})$. Gas sensing test was performed on the HW-30A system (Hanwei Electronics Co. Ltd., PR China).

\section{Results and discussions}

\section{Morphology, structure and composition characterization}

The XRD results of the as-prepared $\mathrm{WO}_{3}, \mathrm{~W}_{19} \mathrm{O}_{55}, \mathrm{~W}_{5} \mathrm{O}_{14}$, and $\mathrm{W}_{18} \mathrm{O}_{49}$ are present in Fig. 1. Fig. 2 illustrates the SEM and HRTEM images of the samples. Grown at different temperatures, the pristine $\mathrm{WO}_{3}$ crystal exhibits irregular rod-like shape as shown in Fig. 2(a) and the $\mathrm{W}_{19} \mathrm{O}_{55}, \mathrm{~W}_{5} \mathrm{O}_{14}$, and $\mathrm{W}_{18} \mathrm{O}_{49}$ samples show the similar micro and nano rod shapes with flat and smooth surface. The crystal nucleus grows promptly along

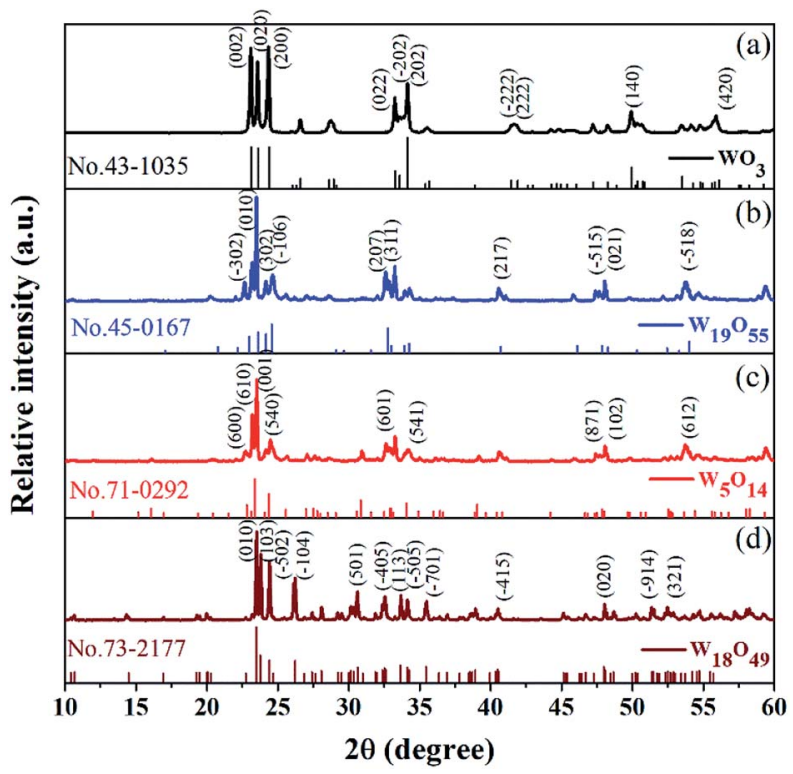

Fig. 1 XRD curves of the as-prepared $\mathrm{WO}_{3}$ and sub-stoichiometric $\mathrm{WO}_{3-x}$, with standard JCPDS card marked below the corresponding curves.

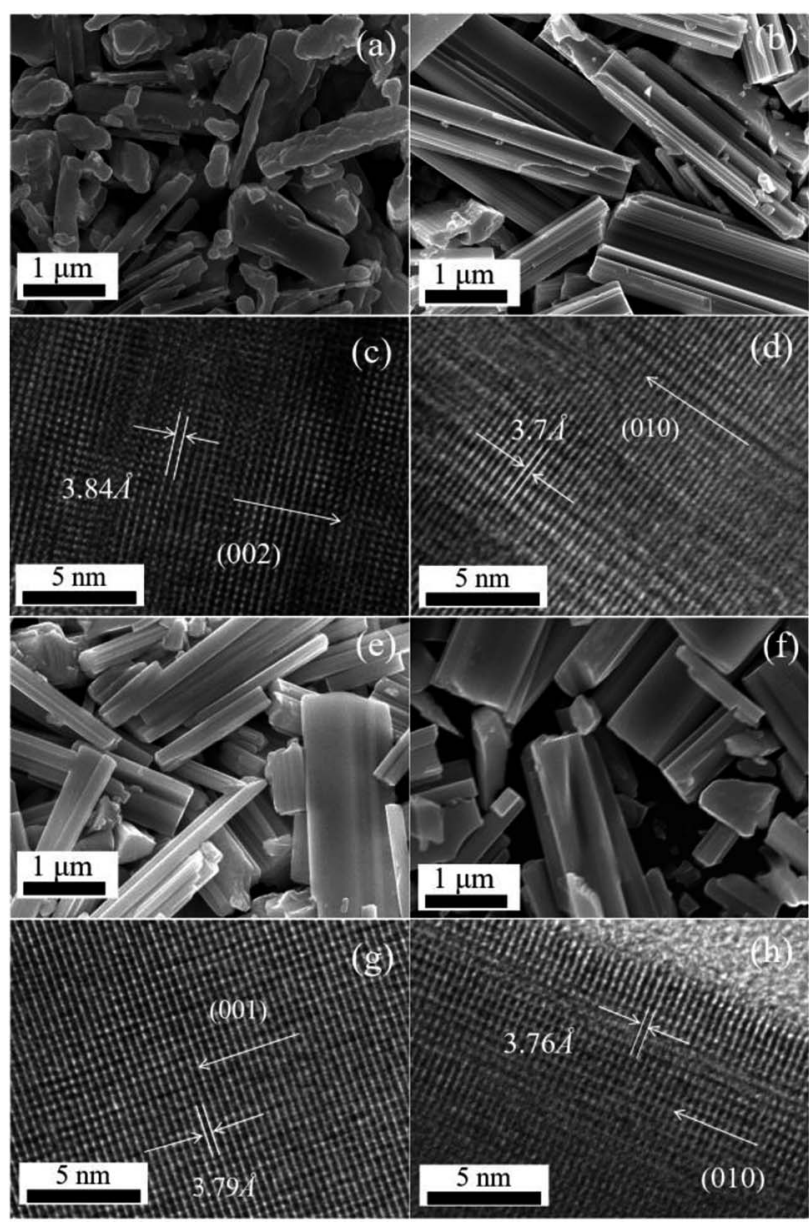

Fig. 2 SEM morphologies and HRTEM images of $\mathrm{WO}_{3}$ (a and c), $\mathrm{W}_{19} \mathrm{O}_{55}$ (b and d), $\mathrm{W}_{5} \mathrm{O}_{14}$ (e and g), $\mathrm{W}_{18} \mathrm{O}_{49}$ ( $f$ and $\mathrm{h}$ ).

the preferential growth direction, leading to such symmetric structures. The sub-stoichiometric $\mathrm{W}_{19} \mathrm{O}_{55}, \mathrm{~W}_{5} \mathrm{O}_{14}$, and $\mathrm{W}_{18} \mathrm{O}_{49}$ are well crystalline with clear grain boundaries and ordered crystal planes as shown in Fig. 2(b-d). The diffraction curve recorded in Fig. 1(a) (black line) can be well indexed to the phase of monoclinic $\mathrm{WO}_{3}$ (JCPDS no. 43-1035), with three main diffraction peaks located at $2 \theta=23.12,23.59$, and $24.38^{\circ}$, corresponding to the preferential growth directions of [002], [020], [200], respectively. The (002) plane with d-spacing of $3.84 \AA$ is further demonstrated by the HRTEM image in Fig. $2(\mathrm{e}){ }^{27}$ The blue curve in Fig. 1(b) matches well with $\mathrm{W}_{19} \mathrm{O}_{55}$ (JCPDS no. 450167) and the strongest diffraction peak located at $2 \theta=23.47^{\circ}$ corresponds to the (010) facet with an interlayer distance of 3.7 $\AA$ as shown in Fig. 2(f). ${ }^{28}$ The diffraction peaks of the red curve in Fig. 1(c) are in good agreement with JCPDS no. 71-0292 file for $\mathrm{W}_{5} \mathrm{O}_{14}$. The main peak located at $2 \theta=23.41^{\circ}$ suggests the (001) planes with interlayer distance of $3.797 \AA$, which is a close match to the HRTEM result of $3.79 \AA$ in Fig. $2(\mathrm{~g})$. The $\mathrm{W}_{5} \mathrm{O}_{14}$ sample grown in a longitudinal direction along the (001) crystallographic axis has the high aspect ratio of nanorods as shown in the SEM image. ${ }^{24}$ At last, Fig. 1(d) depicts the XRD curve of monoclinic $\mathrm{W}_{18} \mathrm{O}_{49}$ (JCPDS no. 05-0392) with the main peak located at $23.45^{\circ}$ corresponding to (010) planes, and the 
interlayer distance of $3.8 \AA$ is consistent with the HRTEM value, $3.76 \AA$, as depicted in Fig. $2(\mathrm{~h}) .^{18,19,29}$

X-ray photoelectron spectroscopy (XPS) provides an appropriate solution to investigate the chemical composition and element states. As we know, tungsten has a complex distribution of $\mathrm{W} 4 \mathrm{f}$ binding energies consisted of three pairs of doublets (six peaks). As exhibited in Fig. 3(a-d), the thin black line is raw data and the red one is the result of smooth fitting. The first doublet peaks (blue line) locate at $37.85 \mathrm{eV}$ and $35.75 \mathrm{eV}$ corresponding to $\mathrm{W} 4 \mathrm{f}_{5 / 2}$ and $\mathrm{W} 4 \mathrm{f}_{7 / 2}$, which confirms that the $\mathrm{W}$ ions are dominated by $\mathrm{W}^{6+}$ in $\mathrm{WO}_{3}$. $\mathrm{No} \mathrm{W}^{5+}$ and $\mathrm{W}^{4+}$ peaks are observed in Fig. 3(a). However, on the other three samples synthesized at $950,1050,1150{ }^{\circ} \mathrm{C}$, we observe the mixture of $\mathrm{W}^{6+}, \mathrm{W}^{5+}$ and $\mathrm{W}^{4+}$ oxidation states. As revealed in Fig. 3(b), the second doublet peaks (green dot-curve) appearing at 36.85 and $33.85 \mathrm{eV}$ are attributed to the $\mathrm{W}^{5+}$ state. The third doublet peaks occur at 35.25 and $32.5 \mathrm{eV}$ (see the navy dot line), implying the presence of the $\mathrm{W}^{4+}$ oxidation state. ${ }^{26}$ Thus, as shown by Fig. 3, the contents of $\mathrm{W}^{5+}$ and $\mathrm{W}^{4+}$ tend to increase gradually with increasing growth temperature. Moreover, we have concluded the O 1s-level XPS spectra of the four $\mathrm{WO}_{3-x}$ samples in Fig. $3(\mathrm{e}-\mathrm{h})$, the thin black line is raw data and the red one is the sum of four deconvolution spectra. The first peak (blue line) locate at $530.9 \mathrm{eV}$ corresponding to oxygen atoms $\mathrm{O}^{2-}$ in the lattice, and the second peak (green line) locate at $532 \mathrm{eV}$ corresponding to adsorbed oxygen species and oxygen state $\mathrm{O}^{1-} \cdot{ }^{30,31}$ Metal oxide surfaces that are exposed to the atmosphere are always hydrated, so that hydroxyl groups $(-\mathrm{OH})$ and water molecules $\left(\mathrm{H}_{2} \mathrm{O}\right)$ signals are also found at 531.4, $532.8 \mathrm{eV}$, respectively. ${ }^{31}$ Our XPS results are in perfect agreement with the report by A. P. Shpak in $2007 .{ }^{31}$

As we can see in Fig. 3(e), oxygen states of $\mathrm{O}^{2-}$ are dominated in $\mathrm{WO}_{3}$ sample, the content of $\mathrm{O}^{1-}$ or remnants of adsorbed oxygen species are much smaller than that of $\mathrm{O}^{2-}$ state.
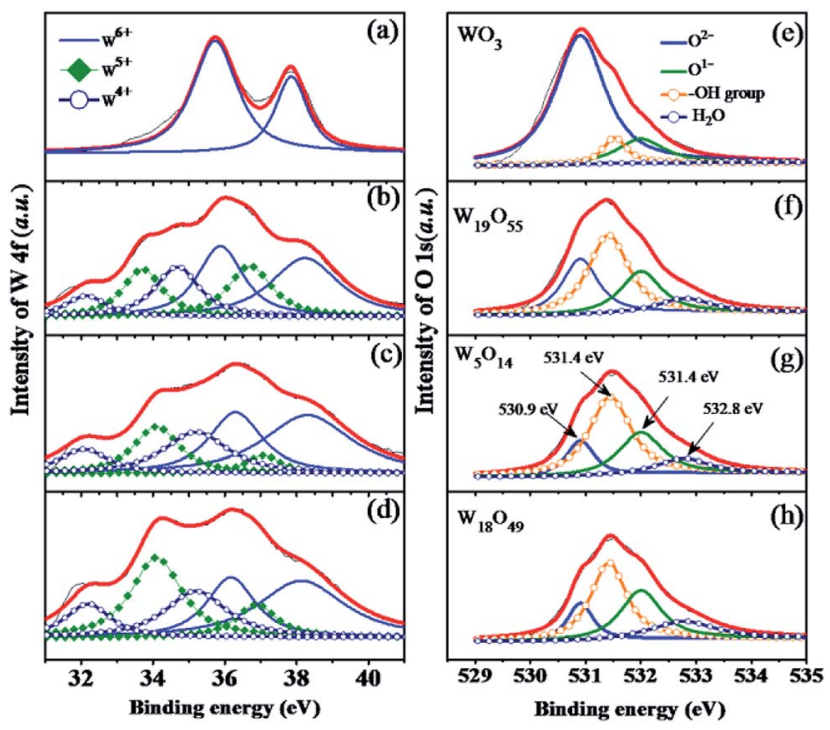

Fig. $3(\mathrm{a}-\mathrm{d})$ The W 4f-level and (e-h) O 1s-level XPS deconvolution spectra of the as-prepared sub-stoichiometric tungsten oxides, $\mathrm{WO}_{3}$, $\mathrm{W}_{19} \mathrm{O}_{55}, \mathrm{~W}_{5} \mathrm{O}_{14}$, and $\mathrm{W}_{18} \mathrm{O}_{49}$.
However, the intensity ratio of $\mathrm{O}^{2-} / \mathrm{O}^{1-}$ is increasing continuously from $\mathrm{WO}_{3}$ to $\mathrm{W}_{18} \mathrm{O}_{49}$, which further confirms the enhanced oxygen adsorption performance in the substoichiometric tungsten oxide. This is the main reason why sensing performance is improved in $\mathrm{WO}_{3-x}$ samples. However, the adsorption of $\mathrm{H}_{2} \mathrm{O}$ molecules in atmosphere and the formation of $-\mathrm{OH}$ groups are also enhanced in the nonstoichiometric $\mathrm{WO}_{3-x}$, which is supposed to suppress the sensing process. This explains why our sensing response of $\mathrm{WO}_{3-x}$ samples are improved but with a limited improvement.

From the Raman curves in Fig. 4, Raman characteristic peaks of $\mathrm{WO}_{3}$ are very clearly exhibited at $806 \mathrm{~cm}^{-1}, 716 \mathrm{~cm}^{-1}$, $326 \mathrm{~cm}^{-1}$ and $272 \mathrm{~cm}^{-1} \cdot{ }^{28,31}$ However, much wider peaks are observed at 300 and $800 \mathrm{~cm}^{-1}$ on the sub-stoichiometric tungsten oxide samples. Due to the distortions in the crystalline structure, it is difficult to assign each of the bands to certain vibrations, particularly for the bands below $300 \mathrm{~cm}^{-1}$ which might be deconvoluted into several deformation and lattice vibrations. As exhibited in Fig. 4(b-d), the main bands of $\mathrm{W}_{19} \mathrm{O}_{55}, \mathrm{~W}_{5} \mathrm{O}_{14}$, and $\mathrm{W}_{18} \mathrm{O}_{49}$ are located at $816 \mathrm{~cm}^{-1}, 805 \mathrm{~cm}^{-1}$ and $801 \mathrm{~cm}^{-1}$, respectively. The main band shifts to lower wave number (lower energy) with increasing $x$ value, indicating that more content of reduced tungsten state $\left(\mathrm{W}^{4+}, \mathrm{W}^{5+}\right)$ were formed in the sub-stoichiometric phases..$^{28,29,32}$

\section{Gas sensing properties and discussion}

The as-grown sub-stoichiometric tungsten oxides have stable chemical properties and have become an alternative platform to investigate the behaviour of oxygen vacancies in metal-oxides based gas sensors. ${ }^{23}$ Fig. 5 shows temperature-dependent sensitivity curves of $\mathrm{WO}_{3}$ (a), $\mathrm{W}_{19} \mathrm{O}_{55}$ (b), $\mathrm{W}_{5} \mathrm{O}_{14}$ (c), and $\mathrm{W}_{18} \mathrm{O}_{49}$ (d) when the sensors are exposed to different concentrations of $\mathrm{H}_{2} \mathrm{~S}(1,2,3,4,10,50 \mathrm{ppm})$, marked in different shades of colours. Firstly, it is found that the low-temperature performance of the sub-stoichiometric $\mathrm{WO}_{3-x}$ sensors has a tendency to improve as the $x$ value increases. The $\mathrm{WO}_{3}$ and $\mathrm{W}_{19} \mathrm{O}_{55}$ sensors show high response at temperature above $380{ }^{\circ} \mathrm{C}$, while the $\mathrm{W}_{5} \mathrm{O}_{14}$ and $\mathrm{W}_{18} \mathrm{O}_{49}$ sensors hold the best

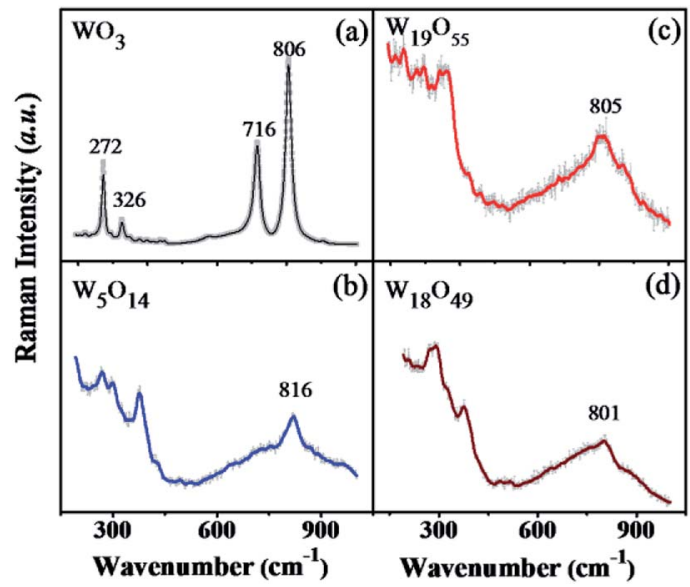

Fig. 4 The Raman spectra of the prepared sub-stoichiometric tungsten oxides, $\mathrm{WO}_{3}$ (a), $\mathrm{W}_{19} \mathrm{O}_{55}$ (b), $\mathrm{W}_{5} \mathrm{O}_{14}$ (c), and $\mathrm{W}_{18} \mathrm{O}_{49}$ (d). 

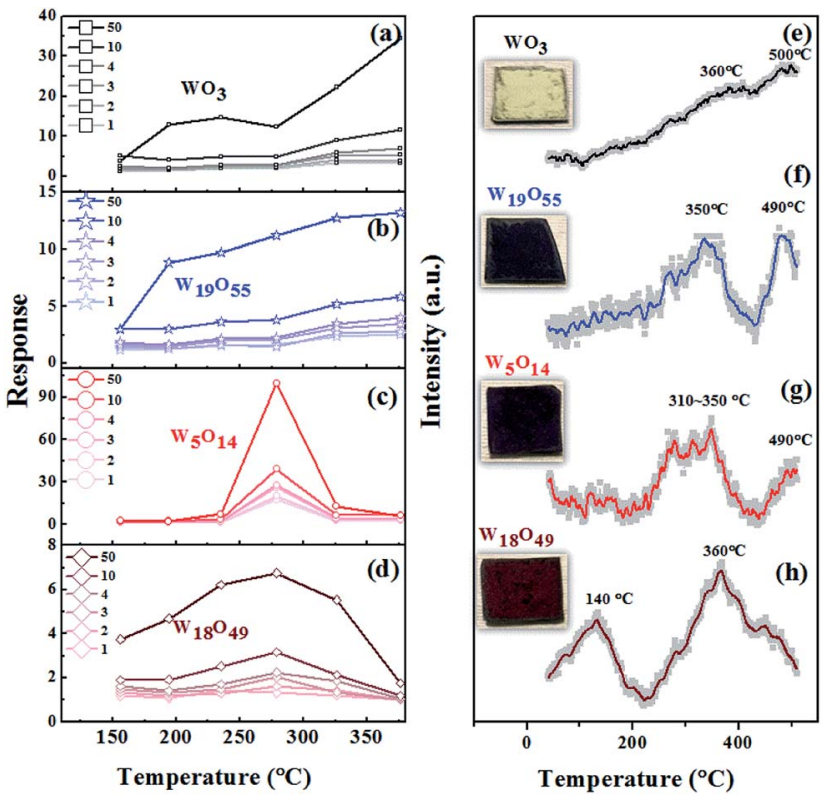

Fig. $5(a-d)$ Temperature-dependent response curves of the gas sensors based on $\mathrm{WO}_{3}$, sub-stoichiometric $\mathrm{W}_{19} \mathrm{O}_{55}, \mathrm{~W}_{5} \mathrm{O}_{14}$, and $\mathrm{W}_{18} \mathrm{O}_{49}$ when exposed to different concentrations of $\mathrm{H}_{2} \mathrm{~S}(1,2,3,4,10$, $50 \mathrm{ppm}$, marked in different shades of colour). (e-h) The $\mathrm{O}_{2}$-TPD profiles for the four sensors and their corresponding photographs presented next to the curves.

performance approximately at $280{ }^{\circ} \mathrm{C}$. The $\mathrm{W}_{18} \mathrm{O}_{49}$ sensor presents a broad band sensitivity curve with a broad shoulder extending to the low temperature side ranging from 150 to $250{ }^{\circ} \mathrm{C}$ approximately. $\mathrm{W}_{18} \mathrm{O}_{49}$ has the highest density of oxygen vacancies among the tested sensors, suggesting that lowtemperature sensing performance could be improved as a result of increasing concentration of oxygen vacancies. Thus, oxygen deficiency facilitates chemisorption of oxygen molecules on the $\mathrm{WO}_{3-x}$ surface. The $\mathrm{W}_{5} \mathrm{O}_{14}$ sensor has a narrow temperature-dependent response curve with its highest response at around $280{ }^{\circ} \mathrm{C}$. As a general trend, it is found that increasing oxygen vacancies give rise to enhanced device performance at low temperature as shown in Fig. 5(a-d), which is beneficial for applications.

To understand the oxygen absorption behaviours of the substoichiometric tungsten oxide sensors, Fig. 5(e-h) display the temperature programmed desorption $\left(\mathrm{O}_{2}\right.$-TPD) profiles of the $\mathrm{WO}_{3-x}$ sensors, together with their photographs presented next to their corresponding curves. As the temperature increases, ambient oxygen molecules that are adsorbed on the tungstenoxide surfaces undergo changes following the sequence of $\mathrm{O}_{2}$ $\rightarrow \mathrm{O}_{2}{ }^{-} \rightarrow \mathrm{O}^{-} \rightarrow \mathrm{O}^{2-}{ }^{2}$ Physically adsorbed oxygen molecules $\left(\mathrm{O}_{2}\right)$ make ignorable contribution to gas sensing. The peaks of chemisorbed oxygen species $\left(\mathrm{O}_{2}^{-}, \mathrm{O}^{-}, \mathrm{O}^{2-}\right)$ are reported to centre around 400,600 and $>700{ }^{\circ} \mathrm{C}$ on the TPD curves..$^{33}$ Thus, Fig. 5(e) shows that the pristine $\mathrm{WO}_{3}$ exhibits a broad desorption bands around 360 and $500{ }^{\circ} \mathrm{C}$, attributed to the chemisorption of oxygen species $\mathrm{O}_{2}{ }^{-}$and $\mathrm{O}^{-}$. For the $\mathrm{W}_{19} \mathrm{O}_{55}$ sensor, the two peaks are shifted to lower temperature positions at $\sim 350$ and $\sim 490$, as shown in Fig. 5 (f). In the case of $\mathrm{W}_{5} \mathrm{O}_{14}$,
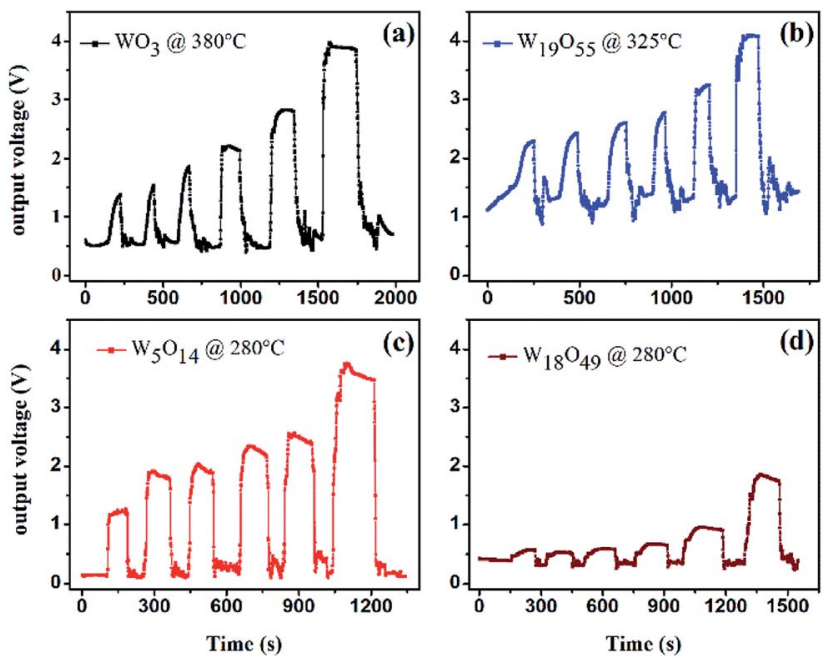

Fig. 6 Dynamic response curves of the sub-stoichiometric $\mathrm{WO}_{3-x}$ sensors: (a) $\mathrm{WO}_{3}$ at $380{ }^{\circ} \mathrm{C}$, (b) $\mathrm{W}_{19} \mathrm{O}_{55}$ at $325{ }^{\circ} \mathrm{C}$, (c) $\mathrm{W}_{5} \mathrm{O}_{14}$ and (d) $\mathrm{W}_{18} \mathrm{O}_{49}$ at $280{ }^{\circ} \mathrm{C}$ after exposed to $1,2,3,4,10,50 \mathrm{ppm} \mathrm{H}_{2} \mathrm{~S}$.

strong peaks are observed at $310-350{ }^{\circ} \mathrm{C}$ (see Fig. $5(\mathrm{~g})$ ), while the peak at $\sim 490{ }^{\circ} \mathrm{C}$ is rather weak. This indicates that a large amount of oxygen ions are chemisorbed in $310-350{ }^{\circ} \mathrm{C}$, which might explain why there is a relatively strong response peak at $\sim 280{ }^{\circ} \mathrm{C}$, close to $310-350{ }^{\circ} \mathrm{C}$ where there are a lot of chemisorbed oxygen ions. As $x$ increases to $0.28\left(\mathrm{~W}_{18} \mathrm{O}_{49}\right)$, a strong peak occurs at the low temperature of $140{ }^{\circ} \mathrm{C}$ shown by Fig. $5(\mathrm{~h})$. The peak at 350 or $360^{\circ} \mathrm{C}$ remains essentially unchanged. These results indicate that oxygen deficiency enhances chemisorption of oxygen ions on $\mathrm{WO}_{3-x}$ surface at low temperature by offering a large number of chemically active absorption sites, which in turn facilitates the ionosorption process and improves the lowtemperature gas sensing sensitivity. ${ }^{34-36}$ Thus, both the temperature-dependent response curves and the $\mathrm{O}_{2}$-TPD profiles measured on the sub-stoichiometric $\mathrm{WO}_{3-x}$ sensors evidence that the working temperature of the gas sensors can be lowered down by using sub-stoichiometric nano $\mathrm{WO}_{3-x}$.

The $\mathrm{W}_{5} \mathrm{O}_{14}$ sensor presents the best performance over the narrow temperature range around $280{ }^{\circ} \mathrm{C}$. However, $\mathrm{W}_{18} \mathrm{O}_{49}$ possesses the highest concentration of oxygen vacancies among all the sub-stoichiometric $\mathrm{WO}_{3-x}$ ones studied here, and the $\mathrm{W}_{18} \mathrm{O}_{49}$ sensor presents considerable response at low temperature. Obviously, the $x$ value and the sensing sensitivity of the $\mathrm{WO}_{3-x}$ sensor do not have a simple relationship. Some other factors might affect device performance, such as specific surface area, crystallographic planes on the surface, and density of interfacial states, according to the published works. ${ }^{18,37}$ Qin's work suggests that agglomeration of $\mathrm{W}_{18} \mathrm{O}_{49}$ at a comparatively high operating temperature weakens the gas diffusion, which in turn gives rise to low response. ${ }^{34}$ Overall speaking, $\mathrm{W}_{18} \mathrm{O}_{49}$ is a metal-like material with abnormally high carrier concentration. ${ }^{19,38}$ It is expected that the carrier concentration in $\mathrm{W}_{18} \mathrm{O}_{49}$ is comparable to the change of electron population induced by the target gas molecules. This leads to a relatively small resistance change when the sensor is exposed to the target gas, 
compared to the result measured on the $\mathrm{W}_{5} \mathrm{O}_{14}$ sensor. The $\mathrm{W}_{18} \mathrm{O}_{49}$ sensor, with the highest concentration of oxygen vacancies, thus possesses relatively low sensing response compared to the $\mathrm{W}_{5} \mathrm{O}_{14}$ sensor, though its low-temperature performance is quite good.

The response and recovery times of the sensors are also investigated. Fig. 6(a-d) presents the dynamic response curves of the $\mathrm{WO}_{3}, \mathrm{~W}_{19} \mathrm{O}_{55}, \mathrm{~W}_{5} \mathrm{O}_{14}$, and $\mathrm{W}_{18} \mathrm{O}_{49}$ sensors measured by the HW-30A gas sensing test system at given temperatures. The measured response (recovery) times are $67 \mathrm{~s}(65 \mathrm{~s}), 53 \mathrm{~s}(37 \mathrm{~s})$, $21 \mathrm{~s}(11 \mathrm{~s})$, and $32 \mathrm{~s}(15 \mathrm{~s})$ for the $\mathrm{WO}_{3}, \mathrm{~W}_{19} \mathrm{O}_{55}, \mathrm{~W}_{5} \mathrm{O}_{14}$, and $\mathrm{W}_{18} \mathrm{O}_{49}$ sensors, respectively. This overall results show the tendency that the use of sub-stoichiometric tungsten oxides accelerates response-recovery processes.

\section{Conclusions}

We have demonstrated that oxygen deficiencies facilitate the low-temperature oxygen ionosorption process, leading to the improvement of sensing performance of the $\mathrm{WO}_{3-x}$-based gas sensors. High-quality sub-stoichiometric $\mathrm{WO}_{3-x}$ with several $x$ values $\left(\mathrm{WO}_{3}, \mathrm{~W}_{19} \mathrm{O}_{55}, \mathrm{~W}_{5} \mathrm{O}_{14}\right.$, and $\left.\mathrm{W}_{18} \mathrm{O}_{49}\right)$ was synthesized and $\mathrm{H}_{2} \mathrm{~S}$ gas sensors were fabricated using the materials. The $\mathrm{W}_{18} \mathrm{O}_{49}$ sensor shows good device performance in a wide temperature range, particularly at the temperature as low as $150{ }^{\circ} \mathrm{C}$. The $\mathrm{W}_{5} \mathrm{O}_{14}$ gas sensor presents very high response value in a narrow temperature range centred at $280{ }^{\circ} \mathrm{C}$. Our work shows that the sub-stoichiometric $\mathrm{WO}_{3-x}$ can be used to enhance the low temperature sensing performance through controlling the concentration of oxygen vacancies.

\section{Conflicts of interest}

There are no conflicts to declare.

\section{Acknowledgements}

This work is financially supported by National Key R\&D Program of China (2016YFA0202200), National Natural Science Foundation of China (Grant no. 11574335, 61471345, 51772213), the Frontier Science Research Project (Key Programs) of Chinese Academy of Sciences (Grant no. QYZDJSSW-SLH018).

\section{References}

1 A. Gurlo and R. Riedel, Angew. Chem., Int. Ed., 2007, 46, 38263848.

2 A. Gurlo, ChemPhysChem, 2006, 7, 2041-2052.

3 N. H. Al-Hardan, M. J. Abdullah, A. Abdul Aziz, H. Ahmad and L. Y. Low, Vacuum, 2010, 85, 101-106.

4 S. W. Choi, J. Y. Park and S. S. Kim, Nanotechnology, 2009, 20, 465603.

5 X. Song, Z. Wang, Y. Liu, C. Wang and L. Li, Nanotechnology, 2009, 20, 075501.

6 H. G. Moon, Y. S. Shim, D. H. Kim, H. Y. Jeong, M. Jeong, J. Y. Jung, S. M. Han, J. K. Kim, J. S. Kim, H. H. Park,
J. H. Lee, H. L. Tuller, S. J. Yoon and H. W. Jang, Sci. Rep., 2012, 2, 588.

7 D. Zhang, Z. Liu, C. Li, T. Tang, X. Liu, S. Han, B. Lei and C. Zhou, Nano Lett., 2004, 4, 1919-1924.

8 Y. Zhou, G. Xie, T. Xie, H. Yuan, H. Tai, Y. Jiang and Z. Chen, Appl. Phys. Lett., 2014, 105, 033502.

9 J. D. Fowler, M. J. Allen, V. C. Tung, Y. Yang, R. B. Kaner and B. H. Weiller, ACS Nano, 2009, 3, 301-306.

10 L. Xu, R. Xing, J. Song, W. Xu and H. Song, J. Mater. Chem. C, 2013, 1, 2174.

11 Z. Meng, H. Jian Xing and O. Chung Wo, Nanotechnology, 2012, 23, 315503.

12 D. Jung, M. Han and G. S. Lee, ACS Appl. Mater. Interfaces, 2015, 7, 3050-3057.

13 D. Jung, M. Han and G. S. Lee, Sens. Actuators, A, 2014, 211, 51-54.

14 D. B. Migas, V. L. Shaposhnikov and V. E. Borisenko, J. Appl. Phys., 2010, 108, 093714.

15 F. Wang, C. Di Valentin and G. Pacchioni, Phys. Rev. B, 2011, 84, 073103.

16 J. Song, Z.-F. Huang, L. Pan, J.-J. Zou, X. Zhang and L. Wang, ACS Catal., 2015, 5, 6594-6599.

17 Y. Qin, D. Hua and M. Liu, J. Alloys Compd., 2014, 587, 227233.

18 Y. Qin, W. Xie, Y. Liu and Z. Ye, Sens. Actuators, B, 2016, 223, 487-495.

19 S. Cong, F. Geng and Z. Zhao, Adv. Mater., 2016, 28, 1051810528.

20 G. Xi, S. Ouyang, P. Li, J. Ye, Q. Ma, N. Su, H. Bai and C. Wang, Angew. Chem., 2012, 124, 2445-2449.

21 Y. Li, Y. Bando and D. Golberg, Adv. Mater., 2003, 15, 12941296.

22 W. Yu, Y. Sun, T. Zhang, K. Zhang, S. Wang, X. Chen and N. Dai, Part. Part. Syst. Charact., 2016, 33, 15-20.

23 J. Qian, Z. Peng, Z. Shen, Z. Zhao, G. Zhang and X. Fu, Sci. Rep., 2016, 6, 25574.

24 M. Remškar, J. Kovac, M. Viršek, M. Mrak, A. Jesih and A. Seabaugh, Adv. Funct. Mater., 2007, 17, 1974-1978.

25 Z. Shen, Z. Zhao, J. Wen, J. Qian, Z. Peng and X. Fu, J. Nanomater., 2018, 2018, 1-12.

26 Z. Shen, Z. Zhao, J. Qian, Z. Peng and X. Fu, J. Mater. Res., 2016, 31, 1065-1076.

27 C.-Y. Su, H.-C. Lin, T.-K. Yang, C.-H. Chang and C.-K. Lin, Mater. Trans., 2009, 50, 2593-2597.

28 J. Qian, Z. Zhao, Z. Shen, G. Zhang, Z. Peng and X. Fu, RSC Adv., 2016, 6, 8061-8069.

29 K. Thummavichai, L. Trimby, N. Wang, C. D. Wright, Y. Xia and Y. Zhu, J. Phys. Chem. C, 2017, 121, 20498-20506.

30 J. C. Dupin, D. Gonbeau, P. Vinatier and A. Levasseur, Phys. Chem. Chem. Phys., 2000, 2(6), 1319-1324.

31 A. Shpak, M. Korduban, M. M. Medvedskij and V. O. Kandyba, J. Electron Spectrosc. Relat. Phenom., 2007, 156-158, 172-175.

32 C. Jian, L. Dongyu, Z. Weihong, X. Fangyan, Z. Jun, G. Li, L. Xiao, D. Shaozhi and X. Ningsheng, J. Phys. D: Appl. Phys., 2008, 41, 115305. 
33 X. Huang, Y. Peng, X. Liu, K. Li, Y. Deng and J. Li, Catal. Commun., 2015, 69, 161-164.

34 Y. Qin, M. Hu and J. Zhang, Sens. Actuators, B, 2010, 150, 37 C. T. Pan, C. Y. Su and Y. C. Luo, Microsyst. Technol., 2016, 339-345.

35 J. Liu, Y. Gao, X. Wu, G. Jin, Z. Zhai and H. Liu, Sensors, 2017, 38 E. Salje and B. Güttler, Philos. Mag. B, 1984, 50, 607-620. $17,1852$.
36 J. Wu, Q. Huang, D. Zeng, S. Zhang, L. Yang, D. Xia, Z. Xiong and C. Xie, Sens. Actuators, B, 2014, 198, 62-69.

23, 2113-2123. 